\title{
Santiago Medero (compilador), Arquitectura en Marcha 1950-1954. La crítica arquitectónica en el semanario Marcha, Montevideo, Facultad de Arquitectura, Universidad de la República, 2014.
}

\author{
Ana Sánchez Trolliet* \\ Historia, Teoría y Praxis de la Arquitectura y la Ciudad. Instituto de Investigación. Facultad \\ de Arquitectura y Urbanismo. Universidad Nacional de La Plata / CONICET
}


Compilado por Santiago Medero y editado por la editorial de la Universidad de la República, el libro Arquitectura en Marcha, reúne una selección de artículos sobre crítica arquitectónica que fueron publicados en esta consagrada revista uruguaya entre los años 1950 y 1956. La edición en libro de estas notas y editoriales, que constituye un generoso ejemplo de visibilización y puesta en disponibilidad de archivos, supuso un extenso trabajo de transcripción y organización de textos. En efecto, uno de los principales logros de esta compilación lo constituye el hecho de que los artículos publicados originalmente en distintas secciones de crítica dirigidas por los arquitectos Ricardo Saxlund, Leopoldo Carlos Artucio y Ramón Gonzalez Almeida, son presentados en torno a cinco áreas definidas especialmente para esta publicación. En la primera parte, "Fundamentos", los artículos selecciones vuelven visibles los principios arquitectónicos -afines a los del Movimiento Moderno, la carta de Atenas y los CIAM- a los cuales sus autores adscriben. En la segunda sección dedicada a la "Planificación" se transcriben una serie de textos de temas urbanos que permiten ver la pregnancia que tuvieron los difundidos principios del desarrollismo, el planeamiento y la intervención estatal

entre los arquitectos uruguayos en los años cincuenta. La tercera sección, "Crítica de Obras", selecciona una serie de escritos donde a partir del análisis de distintos edificios proyectados y construidos por reconocidos arquitectos uruguayos se evidencia la preocupación de los redactores por hacer de la arquitectura un objeto de apreciación estética entre legos y profesionales. En "Internacionales", la cuarta sección, se incluyen artículos que expresan el interés por comparar otros contextos nacionales a fin de contradecir el consenso sobre la excepcionalidad del caso uruguayo y su interpretación como un escenario social y cultural de avanzada en la región. En la última sección, "Resonancias", se transcriben distintas cartas de lectores donde puede verse las reacciones, en general negativas, que estas columnas despertaban entre quienes leían el semanario. El libro contiene además un pequeño estudio introductorio del autor y un anexo biográfico con énfasis en la vida profesional y, en menor medida, la vida política de los principales redactores de estas columnas.

El semanario Marcha reconocido por ser un medio de construcción y formación de opinión en clave progresista, se convirtió en un faro de proyección continental para los intelectuales seducidos por el antiiperialismo, el latinoamericano y el nacionalismo. En este marco, si bien la sección de arquitectura compartía con la línea editorial de la revista su negativa a aceptar las modas académicas y su visión crítica de la cultura de masas, el interés de estos arquitectos por instalar en Uruguay los postulados internacionalistas de la arquitectura moderna, ofrecía esquemas de interpretación que no siempre convergían con afirmaciones nacionalistas a la hora de considerar la cultura arquitectónica y urbana uruguayas.

Sus redactores apelaban a un público lector diferenciado entre los profesionales y el público general. Cuando se dirigían a sus colegas, estos escritos tenían un carácter propedéutico puesto que sus escritos servían como un canal de enunciación de principios. En cambio, cuando se dirigían al público, considerado como lego, los redactores se sentían llamados a ofrecerle los elementos necesarios para apreciar la arquitectura como un arte. Desde su perspectiva, los habitantes de las ciudades uruguayas estaban mal informados y su falta de competencias para interpretar la arquitectura los hacía vivir irreflexivamente en espacios arquitectónicos funestos.

Estos arquitectos impugnaban que no existieran criterios estéticos consensuados para evaluar a la arquitectura. En tanto que la consideraban el arte más determinante de la vida social, esperaban que sus críticas de obra definieran los criterios del gusto y sentaran un rumbo definido de acción. Almeida, Artucio y Saxlund pretendían intervenir en un panorama profesional que consideraban atrasado. A sus ojos, el campo arquitectónico se encontraba desgastado, poco actualizado y enfocado, según describían, en el mero interés personal. La arquitectura definida como una necesidad social y un servicio público debía adscribir a los principios de la arquitectura moderna. Desde su perspectiva, su racionalidad, su transparencia, su sencillez, su funcionalismo y sus posibilidades de adecuación a las técnicas y los materiales disponibles en una economía rezagada, la convertían en la arquitectura del tiempo presente. Mientras que los usos de estilos del pasado eran considerados peyorativamente y se interpretaban como una recuperación descontextualizada de viejas tipologías, la arquitectura moderna y sus edificios en altura se veían como un antídoto contra la tiranía impuesta por el comitente puesto que sus diseños homogeneizables a distintos individuos permitían una acción creativa libre. Además, la construcción en altura era interpretada como una eficiente solución al problema de la especulación inmobiliaria que veían realizarse en la proliferación de casas bajas cuya multiplicación conducía a una irracional expansión de la ciudad en horizontal.

Con todo, los criterios con los cuales definían los elementos para distinguir la buena de la mala arquitectura parecían estar muy lejos del público medio como demuestra, por ejemplo, las contrarias lecturas sobre la instalación de un edificio de once pisos frente a la costa en Punta del Este. Si bien para los redactores, esta altura era la mejor de las soluciones posibles a los problemas de habitación, uno de los lectores que firmaba con el seudónimo del "criollo indignado" impugnaba a 
este "rascacielos" por romper con la armonía del paisaje costero.

Por último, en reiteradas oportunidades el progresismo cultural de estos arquitectos se entroncaba con una crítica urbana y rural que traslucía lecturas anticapitalistas. Los arquitectos, vislumbrados como los baquianos de un nuevo sistema social, eran interpelados con planteos reformistas que en algunas ocasiones derivaban en una retórica explícitamente marxista. Con todo, los llamados a la reforma agraria y las demandas por la instauración de nuevas formas de gestión de la propiedad presentes en los textos de estilo más principista se diluían cuando se analizaban las obras construidas.

En suma, el libro recupera el mismo llamado de atención que estos arquitectos reclamaban en relación con la falta de pregnancia de los debates arquitectónicos en medios extra disciplinares. Por ello esta compilación constituye un renovado llamado a la interrogación por los debates sobre cultura arquitectónica en la vida intelectual y cultural en Uruguay y, para que esta tarea resulte posible, Medero ofrece un insumo fundamental. 